\title{
ESTIMATING RATES OF DENUDATION USING COSMOGENIC ISOTOPE ABUNDANCES IN SEDIMENT
}

\author{
PAUL BIERMAN \\ Department of Geology, University of Vermont, Burlington, VT 05405, USA \\ ERIC J. STEIG \\ Department of Geology, University of Washington, Seattle, WA, 98195, USA
}

Received 10 January 1994

Accepted 12 January 1995

\begin{abstract}
We propose, as a testable hypothesis, a basin-scale approach for interpreting the abundance of in situ produced cosmogenic isotopes, an approach which considers explicitly both the isotope and sediment flux through a drainage basin. Unlike most existing models, which are appropriate for evaluating in situ produced cosmogenic isotope abundance at discrete points on Earth's surface, our model is designed for interpreting isotope abundance in sediment. Because sediment is a mixture of materials, in favourable cases derived from throughout a drainage basin, we suggest that measured isotope abundances may reflect spatially averaged rates of erosion. We investigate the assumptions and behaviour of our model and conclude that it could provide geomorphologists with a relatively simple means by which to constrain the rate of landscape evolution if a basin is in isotopic steady state and if sampled sediments are well mixed.
\end{abstract}

KEY WORDS Keywords: denudation rate; erosion; hillslope; modelling; cosmogenic isotopes; sediment budget

\section{INTRODUCTION}

In the past several decades, geomorphic research has focused on understanding process mechanics and rates over relatively short time and length scales. Rates of erosion or denudation (mass loss from Earth's surface) are commonly determined with significant uncertainty by measuring the rate of active surface processes (Saunders and Young, 1983) or the mass of material leaving a drainage basin (Milliman and Meade, 1983). Generating long-term rates from these contemporary measurements requires the assumption that process rates are constant. Because much of Earth's surface has been disturbed by human activities and because climate has changed on a variety of time scales, current rates may not be representative of those in the past (Milliman and Meade, 1983). Prior work on sediment routing has considered the flux and storage of sediment in various reservoirs (colluvium, alluvium and the active channel) in order to estimate residence times (Dietrich and Dunne, 1978) and erosion rates (Reneau and Dietrich, 1991; Reneau et al., 1989). These measurements integrate the rate of sediment production and transport over thousands of years but only for small portions of the landscape. There is great uncertainty in extrapolating these rates to large catchments.

Recent technological advances have allowed measurement of isotopes produced at Earth's surface by the bombardment of cosmic rays (Elmore and Phillips, 1987). The abundance of these 'cosmogenic' isotopes, once appropriate background and decay corrections have been made, is proportional to the integrated cosmic ray exposure. Prior application of these isotope systems to geomorphic problems has primarily involved samples collected from specific locations on 'stable' or 'steadily eroding' bedrock surfaces (Lal, 1991; Marti and Craig, 1987; Nishiizumi et al., 1991a; Phillips et al., 1990). Although these discrete data are useful in some geological situations, rates need to be measured at much larger scales in order to (1) 
explain the geomorphic evolution of drainage basins, river systems, and mountain belts, and (2) determine the relationship between erosion and climate and tectonism (Donnelly, 1982; Molnar and England, 1990; Raymo and Ruddiman, 1988).

This paper proposes and begins to evaluate a new, sediment-based approach to determining basin-scale rates of erosion, one which has the potential to broaden the scale at which cosmogenic isotope studies are performed. Our approach is based on interpretive methods proposed by Lal and co-workers (Lal and Arnold, 1985; Lal et al., 1987) and considers the flux of isotopes between reservoirs as proposed for meteoric ${ }^{10}$ Be by Brown et al. (1988). The equations we develop are similar to those developed by Lal $(1988,1991)$ for interpreting isotope abundance at a single point; however, our derivation, and the assumptions inherent to our model, differs because we rely on sediment to integrate conditions over the eroding landscape. The variables we use are defined in the Notation.

\section{COSMOGENIC ISOTOPES}

Isotopes, such as ${ }^{36} \mathrm{Cl},{ }^{10} \mathrm{Be}$ and ${ }^{26} \mathrm{Al}$, are produced in the uppermost several metres of rock and soil primarily by cosmic ray bombardment ( $\mathrm{Lal}, 1988)$. These and other cosmogenic nuclides are also produced in the atmosphere and rain out on rock surfaces; however, methods have been developed to separate meteoric inputs from isotopes produced in situ (Kohl and Nishiizumi, 1992; Leavy, 1987; Nishiizumi et al., 1989). In this paper we consider only the production of isotopes in rock and soil; we assume that samples have been properly treated to remove any atmospherically produced nuclides.

In general, in situ cosmogenic isotope production is highest at Earth's surface and decreases rapidly with depth. The production rate $\left(\boldsymbol{P}_{x}\right)$ at any depth $(x)$ and density of material $(\rho)$ can be estimated if the surface production rate $\left(P_{0}\right)$ is known (Lal, 1991):

$$
P_{x}=P_{0} \mathrm{e}^{-(x \rho / \Lambda)}
$$

The characteristic attenuation factor $(\Lambda)$ has been shown to be roughly invariant at different locations on the earth's surface (Brown et al., 1991b; Lal, 1991), but isotope production rates change with time, altitude, latitude and the geometry of the exposed surface (Lal, 1991).

Prior research using terrestrially produced cosmogenic isotopes has determined primarily erosion rates and/or exposure ages of individual bedrock or boulder surfaces (Bierman, 1994). For example, ${ }^{36} \mathrm{Cl},{ }^{26} \mathrm{Al},{ }^{14} \mathrm{C}$ and ${ }^{10} \mathrm{Be}$ have been used to date landforms and measure erosion rates (Dockhorn et al., 1991; Jull et al., 1992; Klein et al., 1986; Nishiizumi et al., 1991a,b; Phillips et al., 1990, 1991; Zreda et al., 1991). Antarctic, Hawaiian and North American exposure ages and erosion rates have been measured using ${ }^{3} \mathrm{He}$ and, to a lesser extent, ${ }^{21} \mathrm{Ne}(\mathrm{Cer}-$ ling, 1990; 1991; Craig and Poreda, 1986; Kurz, 1986; Kurz et al., 1990; Marti and Craig, 1987).

Cosmogenic exposure ages and erosion rates are model values calculated using the equations shown in Table I and reviewed in Lal (1991). The generation of these model rates and ages depends, sometimes critically, on underlying assumptions (Bierman and Gillespie, 1991, 1992; Lal, 1991). Even though geological observations indicate that some simplifying assumptions such as 'no erosion' or 'steady-state erosion' are not always valid (Bierman and Gillespie, 1991, 1992), cosmogenic isotope measurements have been used to generate geomorphically valuable limiting ages and erosion rates at specific points on the landscape. However, in order to understand the rate at which large-scale landscapes evolve, the erosion rate at many individual points must be measured - an expensive and time-consuming proposition. This paper explores the possibility that basin-scale erosion rates can be determined more easily by measuring isotope concentration in sediment leaving the basin. Our purpose in presenting this model is to stimulate discussion and encourage measurement of cosmogenic isotope abundance in sediment.

\section{INTERPRETIVE MODEL}

Our model considers the flux of sediment and cosmogenic isotopes into and out of various reservoirs on 
Table I. Interpretive models

\begin{tabular}{cccc}
\hline \multicolumn{1}{c}{ Model } & $\begin{array}{l}\text { Material } \\
\text { analyzed }\end{array}$ & Equation & Assumptions \\
\hline $\begin{array}{l}\text { Steady-state erosion } \\
\text { (Lal, 1988, 1991) }\end{array}$ & Rock & $m=\frac{\Lambda\left(P_{0}-N \lambda\right)}{N}$ & $\begin{array}{l}\text { Surface eroding in pieces }<< \\
\text { scale depth of cosmic ray } \\
\text { penetration }\end{array}$
\end{tabular}

Exposure age

(Lal, 1988, 1991)

Rock $\quad t=\frac{-1}{\lambda} \ln \left(1-\frac{N \lambda}{P_{0}}\right)$ following exposure
Steady erosion (Lal, 1988, 1991)

$$
\text { Rock } \quad N=\frac{P_{0}\left(1-\mathrm{e}^{-\left(\lambda+m \Lambda^{-1}\right) t}\right)}{\lambda+m \Lambda^{-1}}
$$

Erosion at a constant rate
since initial exposure

Surface eroding in pieces $<<$ scale depth of cosmic ray penetration

Isotope concentration at first exposure is well characterized

Basin-wide erosion Sediment $\quad \bar{m}=\frac{\Lambda\left(P_{\text {oeff }}^{J}-\bar{C}_{\text {sed }}^{J} \lambda\right)}{\text { rates }}$
$\bar{C}_{\text {sed }}^{J}$ (this paper)

\section{Average concentration is representative}

\section{Erosion rate constant}

Initial concentration well characterized
Result of violated assumption

Calculated rate depends on time since last erosion event. Could be over- or underestimated

Erosion rate overestimated

Exposure age is underestimated

Exposure age could be over- or underestimated

Considering current analytic and production rate uncertainties, age and erosion rate estimates are imprecise (Gillespie and Bierman, 1991)

Calculated erosion rate can be either over- or underestimated

Calculated erosion rate can be either over- or underestimated

Estimates are imprecise and depend heavily on validity of assumed initial concentration

Average concentration is representative

Earth's surface. The crux of our model is the concept of isotopic and, as a result, landscape steady state. If a basin or fluvial system is in isotopic steady-state, the in-going isotope flux $\left(I_{\mathrm{IN}}\right)$ and outgoing isotope flux ( $\left.I_{\text {OUT }}\right)$ are equal. Such equality implies that the size of the isotope reservoir $\left(N_{\text {RES }}\right)$ in the basin does not change. Our model assumes that 'cross-basin' contamination (such as aeolian sediment input) and the 'radiogenic' production of the 'cosmogenic' isotope are either minimal or can be determined.

In our model, the source of isotopes $\left(I_{\mathrm{IN}}\right)$ is in situ production by cosmic ray bombardment; the sinks for isotopes are transport out of the basin $\left(I_{\text {TRAN }}\right)$ in sediment $\left(I_{\text {SED }}\right)$, solution $\left(I_{\text {SOL }}\right)$ and, in the case of unstable isotopes, decay $\left(I_{\mathrm{D}}\right)$. If the basin is in erosional equilibrium or steady-state, the flux of mass $\left(M_{\text {OUT }}\right)$ must also be uniform. Figure 1 portrays this 'isotope balance' graphically. $I_{\text {soL }}$ represents only isotopes produced in situ and released by the weathering process; it does not include those produced in the atmosphere and 


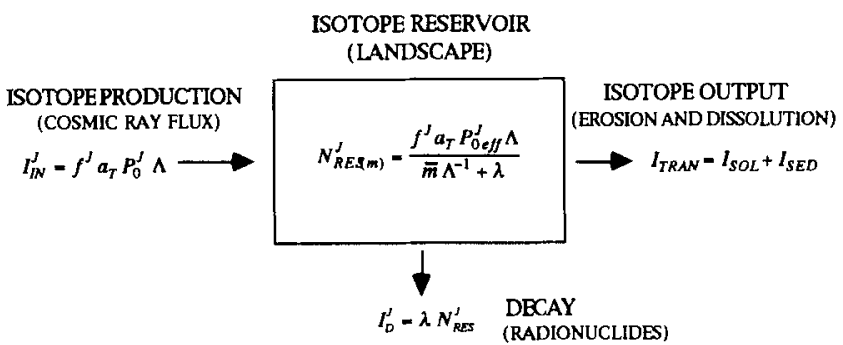

Figure 1. Box model of cosmogenic isotope production and loss from an idealized basin in which mass loss is spatially and temporally uniform

delivered to the basin by precipitation.

$$
I_{\mathrm{IN}}=I_{\mathrm{OUT}}=I_{\mathrm{D}}+I_{\mathrm{TRAN}}=I_{\mathrm{D}}+I_{\mathrm{SOL}}+I_{\mathrm{SED}} \text { and } M_{\mathrm{IN}}=M_{\mathrm{OUT}}=\mathrm{constant}
$$

The use of a specific mineral phase, such as quartz, requires that production rates, sediment fluxes and solute loadings specific to that mineral be used in the model equations we propose. We designate the use of a specific mineral phase with the superscript ' $J$ '.

\section{Basin-wide rates of denudation}

On average, the concentration of in situ produced cosmogenic isotopes in sediment leaving a particular basin is inversely related to the rate at which that basin is eroding. In a rapidly eroding basin, most rock will be exposed to only a small number of cosmic rays before erosion and transport out of the basin; as a result, isotope concentration will be low. In a slowly eroding basin, integrated cosmic ray exposure is much greater and, consequently, isotope concentration will be much higher. The following sections examine these deductions more quantitatively and consider several specific cases in detail.

Implicit in the development of our model are several assumptions (1) the rate of erosion is constant but not necessarily spatially uniform; (2) the basin is in isotopic steady state, (3) sampled sediment is spatially and temporally representative of all sediment leaving the basin, i.e. it is well mixed; (4) mass loss from the basin is occurring primarily by surface lowering; (5) the mineral selected for isotopic analysis is uniformly distributed through the basin.

Although it is difficult to test these assumptions rigorously, common sense suggests that there may be certain landscapes or temporal and spatial scales at which they become increasingly valid. For example, fieldwork can constrain the distribution of lithologies and the processes by which mass loss is occurring over the basin surface. In larger basins, where sediment is supplied by numerous tributary systems, spatial and temporal heterogeneity in isotope concentration will presumably be damped. The assumptions of isotopic and landscape steady-state behaviour are more difficult to evaluate. Many previous denudation-rate studies have assumed steady rates of erosion even though such uniformity is difficult to verify a priori and may be invalid for many landscapes. The assumption of isotopic steady-state is testable but the data are sparse and uncertain. Later in this paper, we examine the likelihood that these assumptions are indeed valid and discuss the sensitivity of our model to their violation.

In-going isotope flux $\left(I_{I N}\right)$. Each year, a certain number of cosmic rays, primarily secondary neutrons, impinge upon a drainage basin. Cosmogenic isotopes are produced at a rate which is directly proportional to the abundance of cosmic rays, an abundance which depends on magnetic field strength, basin altitude, latitude and, for steep-walled basins, gross geometry.

Where elevation and latitude within the basin do not change more than several hundred metres or several degrees, respectively, and slopes are less than $20^{\circ}$, the number of cosmogenic isotopes produced each year in a specific mineralogy $(J)$ can be calculated simply. This calculation integrates isotope production at the ground surface $\left(P_{0}^{J}\right)$ through depth (Equation 1) and considers the basin area $\left(a_{\mathrm{T}}\right)$ and fractional abundance 
$f^{J}$ of the mineral in which isotope concentration is measured.

$$
I_{\mathrm{IN}}^{J}=f^{J} a_{\mathrm{T}} \int_{0}^{\infty} \rho P_{0}^{J} \mathrm{e}^{-\rho x \Lambda^{-1}} \mathrm{~d} x=f^{J} a_{\mathrm{T}} P_{0}^{J} \Lambda
$$

For many moderately sized basins in stable cratons, Equation 3 should approximate reasonably the ingoing isotope flux. However, estimating the annual production of isotopes in terranes having greater relief or extending over many degrees of latitude is more complex. For these basins, a spatially weighted average or effective surface production rate $\left(P_{0 \text { eff }}^{J}\right)$ must be calculated.

In principal, $\left(P_{0 \text { eff }}^{J}\right)$ could be calculated by considering the altitude, latitude and exposure geometry of every point in the basin. In practice, $P_{0 \text { eff }}^{J}$ can be calculated far more simply by considering the basin as discrete subunits, each of which incorporates a smaller range of altitudes $(\sim 100 \mathrm{~m})$ and/or latitudes $\left(5^{\circ}\right)$. In each of these subunits, an average slope can be calculated which will account for the large-scale geometric effect $(G)$ on cosmic ray flux (Nishiizumi et al., 1989). For our model, small-scale surface roughness, a boulder for instance, is unimportant because we are only interested in the total isotope production in a subunit, not the distribution of production within that subunit. Furthermore, because isotope production rates are much more sensitive to changes in elevation than latitude (Lal, 1991), latitude corrections are relatively unimportant in basins spanning less than 5 to $10^{\circ}$.

The effective production rate for a basin can be calculated by considering elevation $(E)$, latitude $(L)$ and geometry $(G)$ correction factors for $\mathrm{n}$ subunits representing the basin. The area of the basin at subunit elevation $z$ is denoted by $a_{i}$.

$$
P_{0 \text { eff }}^{J}=\frac{1}{a_{\mathrm{T}}} \sum_{i=1}^{i=n} a_{i} P_{0}^{J} E_{i} L_{i} G_{i}
$$

Methods for calculating the elevation, latitude and geometry corrections have been presented and are based on theory and contemporary neutron flux data (Lal, 1991); however, the paucity of cosmogenic isotope data from well-dated geomorphic surfaces makes it difficult to determine the actual accuracy and precision of these correction procedures. In heavily vegetated basins, an additional correction (likely only several per cent) could be applied for the cosmic rays absorbed by organic matter before reaching the ground surface.

Isotope inventory within basin $\left(N_{R E S}\right)$. The concept of isotope balance or steady-state is not an intuitive one and requires further elaboration. In order for a basin to be in isotopic steady-state, the in-going and out-going isotope flux must be equal and the reservoir size $\left(N_{\mathrm{RES}}\right)$ must be constant. The isotopic reservoir $\left(N_{\mathrm{RES}}\right)$ is the total number of in situ produced cosmogenic isotopes residing in the basin at a particular time.

In most cases, calculating the size of the isotope reservoir is neither straightforward nor possible. However, if we assume the simplest case - spatially and temporally uniform erosion - we can use Lal's work to calculate reservoir size. Lal (1991) showed that the concentration of in situ produced cosmogenic isotopes $\left(C_{x}\right)$ can be calculated for a point at depth $x$ in a profile if the surface is eroding at a steady rate where $\varepsilon$ is the rate of erosion and $\lambda$ is the decay constant of the measured isotope.

$$
C_{0}=\frac{P_{0}}{\varepsilon \rho \Lambda^{-1}+\lambda} \quad C_{x}=\frac{P_{x}}{\varepsilon \rho \Lambda^{-1}+\lambda}
$$

Although Lal developed this formula by considering a single point on the eroding landscape, by integration it can be used to calculate the mineral-specific isotope inventory $\left(N_{\mathrm{RES}(\mathrm{m})}^{J}\right)$ in an entire basin if the rate of mass loss $(\bar{m})$ is spatially and temporally uniform.

$$
N_{\mathrm{RES}(\mathrm{m})}^{J}=a_{\mathrm{T}} \rho f^{J} \int_{0}^{\infty} \frac{P_{x \text { eff }}^{J}}{\bar{m} \Lambda^{-1}+\lambda} \mathrm{d} x
$$


where

$$
\begin{gathered}
P_{x \text { eff }}=P_{0 \mathrm{eff}} \mathrm{f}^{-\rho x \Lambda^{-1}} \\
N_{\mathrm{RES}(\mathrm{m})}^{J}=\frac{f^{J} a_{\mathrm{T}} P_{0 \mathrm{eff}}^{J} \Lambda \rho}{\rho\left(\bar{m} \Lambda^{-1}+\lambda\right)}=\frac{f^{J} a_{\mathrm{T}} P_{0 \mathrm{eff}}^{J} \Lambda}{\bar{m} \Lambda^{-1}+\lambda}
\end{gathered}
$$

It is tempting to apply Equation 7 to a landscape in which the erosion rates are spatially non-uniform by calculating a spatially averaged rate of mass loss $(\bar{m})$ and an effective production rate. Unfortunately, doing so will not provide an accurate estimate of reservoir size. Consider a landscape made up of three blocks, each losing mass at a steady but different rate $\left(m_{1}, m_{2}, m_{3}\right)$ :

$$
\frac{f^{J} a_{1} P_{0}^{J} \Lambda}{m_{1} \Lambda^{-1}+\lambda}+\frac{f^{J} a_{2} P_{0}^{J} \Lambda}{m_{2} \Lambda^{-1}+\lambda}+\frac{f^{J} a_{3} P_{0}^{J} \Lambda}{m_{3} \Lambda^{-1}+\lambda} \neq \frac{f^{J} a_{\mathrm{T}} P_{0 \mathrm{eff}}^{J} \Lambda}{\bar{m} \Lambda^{-1}+\lambda}
$$

The reservoir for each block can be calculated and the sum is found to differ from that calculated using the average erosion rate (Figure 2, Table II). This discrepancy is caused by the relative importance of the decay correction, represented by $\lambda$, which differs in relative importance for each erosion rate. From this observation, we conclude that a particular, spatially averaged erosion rate does not correspond uniquely to an isotope reservoir size; rather, $N_{\mathrm{RES}(\mathrm{m})}^{J}$ is an idiosyncratic function of the spatial variability and magnitude of erosion rates within the basin. Nevertheless, Figure 2, Table II and additional calculations we have made show that for long-lived radionuclides the error introduced by spatial heterogeneity is rather low, particularly at erosion rates $>10 \mathrm{~m} \mathrm{Ma}^{-1}$. In many geological environments the erosion rates are higher than this (Saunders and Young, 1983). The use of stable nuclides, such as ${ }^{3} \mathrm{He}$ and ${ }^{21} \mathrm{Ne}$, bypasses the decay correction altogether.

Out-going isotope flux $\left(I_{\text {OUT }}\right)$. In situ produced cosmogenic isotopes can leave a drainage basin by several means. They can be transported in sediment, dissolved and removed in solution or adsorbed to particle surfaces, and, in the case of unstable nuclides, they can be lost by decay.

Consider the average isotope concentration $\left(\bar{C}_{\text {OUT }}^{J}\right)$ in a specific mineral phase leaving a drainage basin both as a solute and in sediment. This concentration is determined by the mineral-specific mass flux $\left(M_{\text {OUT }}^{J}\right)$ and isotope flux ( $\left.I_{\text {TRAN }}^{J}\right)$ carried out of the basin by transport in sediments $\left(M_{\text {SED }}^{J}\right)$ and in solution $\left(M_{\mathrm{SOL}}^{J}\right)$. The mineral-specific solute flux of an in situ produced isotope is defined as $I_{\text {SOL }}^{J} / M_{\text {SOL }}^{J}$ and represents the loss of that in situ produced isotope from the basin by the chemical weathering and dissolution of sediments and bedrock. It is important to realize that $M_{\text {SOL }}^{J}$ represents only the nuclides resulting from production in situ and released by dissolution of the mineral phase of interest. In most cases, meteoric input

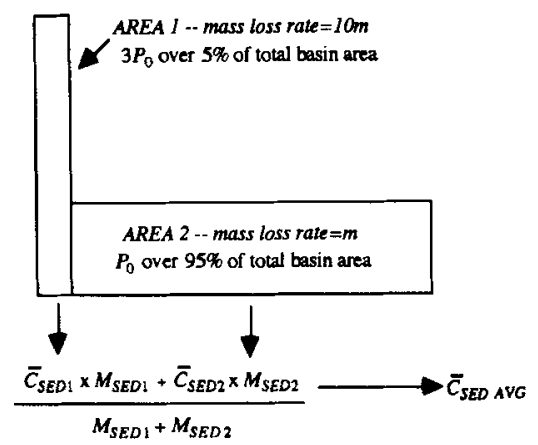

Figure 2. Schematic model of basin having ten-fold higher erosion rate over 5 per cent of area (e.g. mountainous terrain?). Production rate is higher by a factor of three in area of high erosion. Basin area, $10 \mathrm{~km}^{2}$. See Table II for model data 


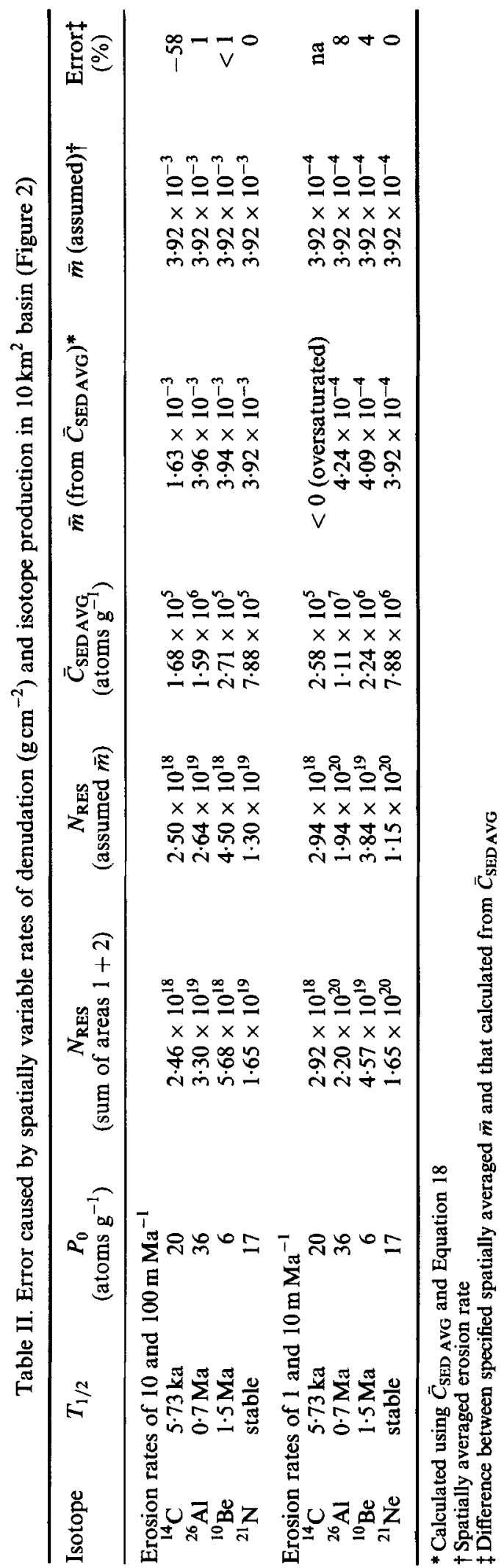


of nuclides produced in the atmosphere will overshadow $M_{\mathrm{SOL}}^{J}$ by orders of magnitude.

$$
\bar{C}_{\text {OUT }}^{J}=\frac{I_{\text {TRAN }}^{J}}{M_{\text {OUT }}^{J}}=\frac{I_{\text {SED }}^{J}+I_{\text {SOL }}^{J}}{M_{\text {SED }}^{J}+M_{\text {SOL }}^{J}}
$$

If we measure isotope abundance in well-mixed sediment leaving a basin, we determine the average isotope abundance in sediment, $\bar{C}_{\mathrm{SED}}^{J}$. If we assume either that there is no loss in solution $\left(I_{\mathrm{SOL}}^{J}\right.$ and $\left.M_{\mathrm{SOL}}^{J}=0\right)$ or that $\bar{C}_{\text {SED }}^{J}=\bar{C}_{\text {SOL }}^{J}$, the case if solution occurs at a similar rate on all grains, then:

$$
\frac{I_{\mathrm{SED}}^{J}}{M_{\mathrm{SED}}^{J}}=\frac{I_{\mathrm{SOL}}^{J}}{M_{\mathrm{SOL}}^{J}} \text { and } \bar{C}_{\mathrm{SED}}^{J}=\frac{I_{\mathrm{SED}}^{J}}{M_{\mathrm{SED}}^{J}}=\bar{C}_{\mathrm{TRAN}}^{J}
$$

The flux of a particular isotope transported out of a basin $\left(I_{\text {TRAN }}^{J}\right)$ is directly proportional to the mass of the mineral leaving the basin $\left(M_{\text {OUT }}^{J}\right)$ and the concentration of the isotope $\left(\bar{C}_{\text {TRAN }}^{J}\right)$ in that mass. The mass of a specific mineral leaving the basin $\left(M_{\text {OUT }}^{J}\right)$ is the product of the spatially averaged rate of mass loss $(\bar{m})$, the basin area $\left(a_{\mathrm{T}}\right)$, and the mineral's abundance $\left(f^{J}\right)$.

$$
\begin{gathered}
I_{\mathrm{TRAN}}^{J}=\bar{C}_{\mathrm{TRAN}}^{J} M_{\mathrm{OUT}}^{J} \text { and } M_{\mathrm{OUT}}^{J}=a_{\mathrm{T}} \bar{m} f^{J} \text { and } \bar{C}_{\mathrm{TRAN}}^{J}=\bar{C}_{\mathrm{SED}}^{J} \\
I_{\mathrm{TRAN}}^{J}=\bar{C}_{\mathrm{SED}}^{J} a_{\mathrm{T}} \bar{m} f^{J}
\end{gathered}
$$

Calculation of basin-wide average denudation rate $(\bar{m})$. For a stable cosmogenic nuclide, such as ${ }^{21} \mathrm{Ne}$, the nuclide concentration in outgoing sediment $\left(\bar{C}_{\mathrm{SED}}^{J}\right)$ is inversely proportional to the rate at which mass is removed from the basin $(\bar{m})$. For an unstable nuclide, the situation is more complex because some isotopes are lost to decay, $I_{\text {IN }}^{J}=I_{\text {TRAN }}^{J}+I_{\mathrm{D}}^{J}$.

Initially, we consider the simple case of a stable nuclide lost from a basin only by sediment transport. If the basin has been losing mass at a steady rate and the total isotope flux into and out of the basin are equal, we substitute Equations 3, 4 and 12 to solve for the basin-wide average rate of mass loss:

$$
\begin{gathered}
f^{J} a_{T} P_{0 \text { eff }}^{J} \Lambda=\bar{C}_{\mathrm{SED}}^{J} a_{\mathrm{T}} \bar{m} f^{J} \\
\bar{m}=\frac{\Lambda P_{0 \text { eff }}^{J}}{\bar{C}_{\mathrm{SED}}^{J}}
\end{gathered}
$$

The rate of mass loss $(\bar{m})$ calculated using Equation 14 represents a basin-wide average even if rates of mass loss vary spatially within the basin. The rate is analogous to that which would be calculated by spreading a measured sediment volume of known age back over the landscape from which it was derived. The calculated rate of mass loss can be converted to a soil or bedrock lowering rate using the appropriate density.

If one considers the case of an unstable nuclide, Equation 13 must be modified to include isotope loss by decay.

$$
I_{\mathrm{IN}}^{J}=I_{\mathrm{TRAN}}^{J}+I_{\mathrm{D}}^{J}
$$

In order to account for loss by decay, the basin-wide isotope inventory ( $N_{\mathrm{RES}}^{J}$ ) must be calculated and the decay constant for the isotope $(\lambda)$ considered:

$$
I_{\mathrm{D}}^{J}=\lambda N_{\mathrm{RES}}^{J}
$$

As discussed above, the basin-wide inventory ( $N_{\mathrm{RES}}^{J}$ ) can only be calculated accurately only if the erosion rate is spatially uniform, a geologically unusual circumstance. However, if we accept the assumptions of spatially uniform erosion and $\bar{C}_{\text {SED }}^{J}=\bar{C}_{\text {SOL }}^{J}$, substituting Equations 3, 4, 7 and 12 into Equation 15 and multiplying both sides by $\bar{m} \Lambda^{-1}+\lambda$, we can solve for the rate of mass loss:

$$
\begin{aligned}
a_{\mathrm{T}} P_{0 \mathrm{eff}}^{J} \Lambda f^{J} & =\bar{C}_{\mathrm{SED}}^{J} a_{\mathrm{T}} \bar{m} f^{J}+\lambda \frac{a_{\mathrm{T}} P_{0 \mathrm{eff}}^{J} \Lambda f^{J}}{\bar{m} \Lambda^{-1}+\lambda} \\
\bar{m} & =\frac{\Lambda\left(P_{0 \mathrm{eff}}^{J}-\bar{C}_{\mathrm{SED}}^{J} \lambda\right)}{\bar{C}_{\mathrm{SED}}^{J}}
\end{aligned}
$$


The assumption of spatially uniform erosion rates is restrictive enough that equation 18 will be of diminished utility in many geological situations. However, cosmogenic radionuclides such as ${ }^{26} \mathrm{Al}$ and

${ }^{10} \mathrm{Be}$ may still be useful tools for understanding the cosmic ray exposure history of sediments in terms of basin-wide erosion rates. If erosion rates throughout the basin are high enough (more than several metres per $\mathrm{Ma}$ ) and sediment storage times are short enough ( $<$ several hundred thousand years) the loss by decay for these long-lived isotopes will be minimal and the $I_{\mathrm{D}}^{J}$ term can be neglected. Isotope concentration can then be interpreted using Equation 14 because ${ }^{10} \mathrm{Be}$ and ${ }^{26} \mathrm{Al}$ will behave as 'stable' isotopes.

The equations we have developed for interpreting in situ produced cosmogenic isotope abundance in sediment have the same form as those developed by Lal and others for interpreting isotope abundance at a single point on the landscape (Table I). Although the two sets of equations are developed at widely differing scales using different specific assumptions, the similarity in form is not surprising if one considers that both derivations are based on isotope balance and the maintenance of an isotopic steady-state. Lal's equations for steady-state erosion at a point are derived by integrating the cosmic ray exposure that a parcel of rock receives as erosion moves it towards the surface (Lal, 1991). In Lal's development, isotopes are produced in the column of rock by cosmic rays and lost both by decay and erosion from the rock surface. Our derivation is similar in that it considers isotope production, decay and loss by erosion. It differs in that these isotope fluxes are considered for an entire drainage basin. By considering the basin scale, we (1) suggest that isotope concentrations in sediment can be used to calculate spatially averaged rates of mass loss, and (2) provide a framework for testing empirically the assumptions inherent in such calculations.

\section{Sediment transport}

After eroding off hillslopes, sediment is transported by streams and temporarily stored in alluvial deposits. Sediment samples are collections of grains, each of which has its own particular cosmic ray exposure history both prior to and after entering the fluvial system. Measurements of isotope abundance in samples of sandsize material reflect the average history of thousands of individual grains, whereas measurements made of a single cobble reflect only the idiosyncratic history of that particular piece of sediment.

It is tempting to use cosmogenic isotope abundance to learn more about the rate and character of sediment transport. Unfortunately, the dynamics of sediment movement and storage complicate the interpretation of isotope abundance. For example, during fluvial transport, each grain resides for varying amounts of time and at various depths in bedforms, bars and terraces. In large rivers, much of the cosmic ray flux will be absorbed by the water, lowering the rate at which isotopes are produced. Therefore, over time, each grain experiences a variety of production rates related to burial depth and position in the channel.

In order to illustrate the complexities of interpreting isotope abundance in terms of sediment transport, we present a simple interpretive model. The model assumes that when a packet of sediment enters a channel reach, it contains a certain abundance of cosmogenic nuclides $\left(C_{\text {init }}\right)$. Isotope production during subsequent storage and transport is a function of effective production rate and exposure duration. Exposure duration $\left(t_{\mathrm{t}}\right)$ reflects the average time taken by grains in a sample to transit a particular reach. Effective production rate $\left(P_{\mathrm{teff}}\right)$ is determined by the depth at which the grains have been transported. Unless one of these variables can be determined independently, deconvolving the effects of burial depth and transit time requires measuring two isotopes having different half-lives and solving two model equations simultaneously.

The simultaneous solution for two isotopes is analogous to the general problem of exposure and steady erosion (Lal, 1988; 1991; Nishiizumi et al., 1991a). Although two isotope solutions are tractable, uncertainty in measurement and production rates causes the results to be quite imprecise (Gillespie and Bierman, 1991; Nishiizumi et al., 1991a). If geological evidence can be used to constrain the magnitude of either $t_{\mathrm{t}}$ or $P_{\mathrm{t} \text { eff }}$, then the problem is simplified and a solution can be stated with higher precision, although the accuracy depends on the validity of the geological interpretation. In addition to measurement uncertainties, the isotope concentration at the beginning of transport must be constrained by field measurement and the untestable assumption of similar input concentration in the past.

The change in isotope concentration $(N)$ as a function of transport time $\left(t_{t}\right)$ reflects both the effective rate 
of production during transit $\left(P_{\mathrm{teff}}\right)$ and, in the case of a radionuclide, decay.

$$
\frac{\mathrm{d} N}{\mathrm{~d} t_{\mathrm{t}}}=P_{\mathrm{teff}}-N \lambda
$$

We integrate Equation 19 with respect to transit time $\left(t_{\mathrm{t}}\right)$ and solve for $c$, the constant of integration at $t_{\mathrm{t}}=0$ and $C=C_{\text {init }}$.

$$
\begin{gathered}
t_{\mathrm{t}}=-\frac{1}{\lambda} \ln \left(P_{\mathrm{t} \text { eff }}-C \lambda\right)+c \quad c=\frac{1}{\lambda} \ln \left(P_{\mathrm{t} \text { eff }}-C_{\text {init }} \lambda\right) \\
t_{\mathrm{t}}=-\frac{1}{\lambda} \ln \left(P_{\mathrm{t} \text { eff }}-C \lambda\right)+\frac{1}{\lambda} \ln \left(P_{\mathrm{t} \text { eff }}-C_{\text {init }} \lambda\right) \quad t_{\mathrm{t}}=\frac{1}{\lambda} \ln \left(\frac{P_{\mathrm{t} \text { eff }}-C_{\text {init }} \lambda}{P_{\mathrm{t} \text { eff }}-C \lambda}\right)
\end{gathered}
$$

From the effective production rate, $P_{\mathrm{teff}}$, an effective depth of irradiation during transport $\left(x_{\mathrm{eff}}\right)$ can be calculated using Equation 1:

$$
x_{\mathrm{eff}}=-\frac{\Lambda}{\rho} \ln \left(\frac{P_{\mathrm{t} \text { eff }}}{P_{0 \text { eff }}}\right)
$$

The effective depth $\left(x_{\text {eff }}\right)$ is not straightforward to interpret geomorphically. For instance, $x_{\text {eff }}$ for a packet of sediment $(e=1 \cdot 3)$ which spent of half its transit time at the surface and half at a depth of $10 \mathrm{~m}$ would be the same as $x_{\text {eff }}$ for a packet of sediment which travelled consistently at a depth of about $1 \mathrm{~m}$.

The complexities and uncertainties resulting from long-term sediment storage during transport down-river may well preclude the interpretation of in situ produced isotope abundances in terms of sediment transit times, particularly in large river systems.

\section{VALIDITY OF MODEL ASSUMPTIONS}

Several important assumptions constrain the development and application of our model. First, isotope concentration in sediment samples must be representative of isotope concentration in all mass leaving the basin. Second, sediment transport and production must occur at a constant rate. Below, we use geomorphic observations and simple modelling to argue that there may be landscapes and length scales at which these assumptions are sufficiently valid to allow calculation of meaningful estimates of basin-wide average erosion rates.

\section{Is the measured isotope concentration representative?}

There are certain geomorphic environments in which sediment is more likely to be well mixed and representative of the basin-wide average value. For example, if most sediment is delivered to the channel by slow and relatively continuous processes, such as soil creep, isotope concentration in sediment sampled from a particular place will not vary greatly over time. However, if most sediment is delivered to the channel by episodic, deep-seated landslides, 'isotope-poor' packets of sediment will periodically inundate the stream. The degree to which these discrete sediment delivery events skew measured isotope abundances will depend on landslide frequency and size, the cosmic ray exposure of the material before landsliding, the proportion of the annual sediment load delivered by landslides, and the efficiency with which sediments are mixed during transport downstream.

We suspect that both spatial and temporal variability in isotope concentration will be inversely related to stream order. Low-order tributary streams and the adjacent hillslopes are usually steep. Sediment is stored in the channel for periods averaging only hundreds of years before being scoured downstream (Benda and Dunne, 1987). Conversely, high-order streams are generally less steep. Lower gradients slow sediment transport, increase sediment storage volume and time in floodplains, and make less likely direct sediment input by episodic mass movements (Dietrich and Dunne, 1978). In addition, sediment in higher-order streams is a mixture of sediment delivered by low-order tributaries. Such mixing, along with longer average sediment 
residence times in higher-order streams, should reduce the variability in isotope concentration by lessening the effect of sediment input from any particular tributary. To the extent that the sampled sediment is well mixed and therefore representative, the basin-wide average rate of erosion will be calculated more accurately. However, if sediment storage time approaches the half life of the isotope being measured, the calculated erosion rate will be less accurate.

\section{Can erosion rate be considered constant?}

The variability of past denudation rates is difficult to determine directly. There are landscapes, such as those that have been glaciated or those that have experienced significant climate changes, for which the rate of denudation is likely to have changed significantly with time. If basin-wide erosion occurs episodically, model denudation rates will be a function of the time since the last erosion event occurred and may actually over- or underestimate long-term rates of denudation (Figure 3 ). If denudation rate changes with time, the isotope systems, unlike sediment yield, can be buffered in their response. For example, stripping of shallow surface soils could dramatically increase sediment yield while only marginally decreasing the average abundance of cosmogenic nuclides in the sediment. Conversely, deep gullying would both increase the sediment yield and decrease significantly isotope abundance as soil and weathered regolith, previously shielded from cosmic rays, were eroded.
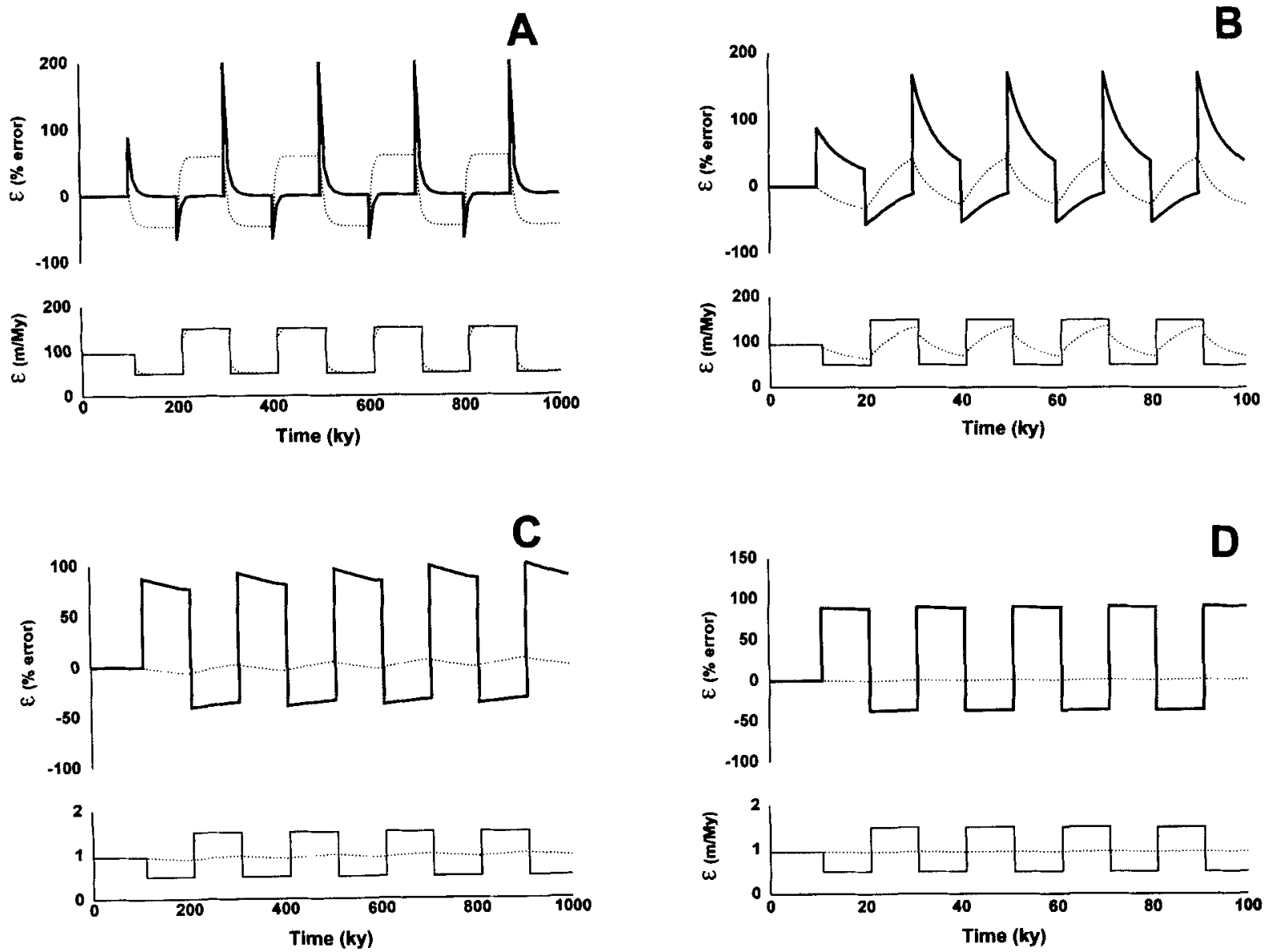

Figure 3. Error in erosion rate calculated from isotope concentration in sediment under conditions where erosion rate changes as a step function: (A) $200 \mathrm{ka}$ cycles of 50 and $150 \mathrm{~m} \mathrm{Ma}^{-1}$ erosion rates; (B) $20 \mathrm{ka}$ cycles of 50 and $150 \mathrm{~m} \mathrm{Ma}^{-1}$ erosion rates; (C) $200 \mathrm{ka}$ cycles of 0.5 and $1.5 \mathrm{~m} \mathrm{Ma}^{-1}$ erosion rates; (D) $20 \mathrm{ka}$ cycles of 0.5 and $1.5 \mathrm{~m} \mathrm{Ma}^{-1}$ erosion rates. Lower portion of each diagram shows actual rate (solid line) and 'mean' erosion rate calculated from isotope abundance (dotted line). Upper portion shows per cent error of calculated rate relative to instantaneous erosion rate (bold line) and relative to long-term average erosion rate (dotted line) 
The amount of time which must pass before isotope abundance reflects a new rate of erosion is controlled by the isotope half-life and the slower of the two denudation rates. The magnitude of the inaccuracy introduced by changing denudation rates or by episodic erosion depends on the denudation rate, the depth and temporal spacing of erosion events, and the half-life of the measured isotope. Simple calculations that we have made suggest that shallow soil loss $(0.5 \mathrm{~m})$ caused by human activity will change calculated denudation rates by $<30$ per cent.

We have made calculations which illustrate the response of an idealized drainage basin to three-fold changes in erosion rate (Figure 3). These calculations assume analysis of a stable isotope, well-mixed sediment $\left(\bar{C}_{\text {SED }}^{J}=\bar{C}_{\text {SOL }}^{J}\right)$ and no sediment storage. Changing erosion rates in a step function at $10 \mathrm{ka}$ and $100 \mathrm{ka}$, we consider the departure of the sediment-based denudation rate from both the long-term average and the time-specific rate of denudation. We made these calculations by solving analytically the depth vs. isotope abundance equations of Lal for changing erosion rates. Per cent error is calculated as the difference between the erosion rate calculated from the isotope concentration in sediment and the current and long-term average erosion rates.

Our calculations (Figure $3 \mathrm{~A}, \mathrm{~B})$ show that at relatively high erosion rates $\left(50-150 \mathrm{~m} \mathrm{Ma}^{-1}\right)$, isotope concentrations in sediment will respond rapidly $(10-20 \mathrm{ka})$ to a three-fold change in erosion rate. At lower erosion rates $\left(0.5-1.5 \mathrm{~m} \mathrm{Ma}^{-1}\right)$ the response time is much longer and isotope concentration remains out of equilibrium with the current erosion rate after $100 \mathrm{ka}$ (Figure $3 \mathrm{C}, \mathrm{D}$ ).

The response time of isotope concentration to changes in erosion rate is directly related to the rate at which denudation is occurring. After 2-3 m of material have been removed from the land surface, memory of the prior erosion rate is effectively erased, error in relation to the present erosion rate is minimized and error in relation to the long-term average erosion rate is maximized. Conversely, if less than $2 \mathrm{~m}$ of material are removed during an erosion cycle, isotope concentration will not reach equilibrium with the new erosion rate and deviation from the long-term average will be minimized. These calculations are encouraging because they suggest that in cases where isotope concentration does not reach equilibrium with the new erosion rate, long-term average erosion rates might be estimated with reasonable accuracy.

It is possible to test directly the assumption of steady-state behaviour using Equations 3 and 11 and a stable isotope such as ${ }^{21} \mathrm{Ne}$ (or, at high denudation rates, long-lived radionuclides such as ${ }^{26} \mathrm{Al}$ and ${ }^{10} \mathrm{Be}$ ). Such an approach is directly analogous to that employed by Brown et al. (1988). At steady state, the following equality is valid for stable or long-lived isotopes:

$$
I_{\mathrm{IN}}=I_{\mathrm{OUT}}, \quad f^{J} a_{\mathrm{T}} P_{0 \mathrm{eff}} \Lambda=\tilde{M}_{\mathrm{OUT}}^{J} \bar{C}_{\mathrm{TRAN}}^{J}
$$

Demonstration of steady-state erosion requires quantification of the total mineral-specific mass flux $\left(\bar{M}_{\text {OUT }}^{J}\right)$ from the basin and the isotope concentration in that flux ( $\left.\bar{C}_{\text {TRAN }}^{J}\right)$. The mass flux can be measured using traditional techniques. The isotope concentration representative of all outbound material must be calculated considering the relative amount of material (in particular, the mineral fraction, $J$, in which the isotope concentration is measured) that leaves the basin by solution, suspension and as bedload.

\section{PRACTICAL CONSIDERATIONS}

To the best of our knowledge, few measurements of cosmogenic isotope abundance have been made in sediment. Nishiizumi et al. (1989) report ${ }^{10} \mathrm{Be}$ and ${ }^{26} \mathrm{Al}$ abundances for quartz grains in till, and Lal et al. (1987) report a single ${ }^{10} \mathrm{Be}$ measurement on presumably alluvial diamond in Zaire. We did not calculate model denudation rates for the till samples (Nishiizumi et al., 1989) because they do not meet the steady-state assumptions of our model. The source of the diamonds analysed by Lal is uncertain, precluding meaningful interpretation of the data.

There are several considerations that limit the precision and accuracy of our approach. The production rates of cosmogenic isotopes remain somewhat uncertain. Most production rate calibrations have been made on surfaces no older than Late Pleistocene (Kurz et al., 1990; Nishiizumi et al., 1989; Zreda et al., 1991); yet, there is reasonable evidence that the effective cosmic ray flux and the rates of isotope production have not been constant over both shorter and longer time scales (Kurz et al., 1990; Leavy, 1987; Reedy et al., 
1983; Stuiver and Quay, 1980; Tric et al., 1992). The effect of changes in isotope production rates on calculated rates of erosion will depend, in a complicated fashion, upon the erosion rate, the pattern of production rate changes, and their duration. Because the uncertainties in the assumptions governing our model are significant and because even relatively imprecise erosion rate data would be geomorphically valuable, we have not considered explicitly the variability of isotope production with time. Our approach is supported by data which suggest that ${ }^{26} \mathrm{Al}$ and ${ }^{10} \mathrm{Be}$ production rates over the past million years are grossly similar to those calculated from samples exposed for only the last 10000 years (Brown et al., 1991a; Nishiizumi et al., 1991a).

We are just beginning to measure cosmogenic isotope abundance in sediment and are making our measurements in quartz because it is common and resists dissolution in many weathering environments, a means by which isotope concentration could be biased. The production of ${ }^{26} \mathrm{Al}$ in quartz is sufficiently high that the isotope abundance in sediment resulting from erosion rates $<1 \mathrm{~km} \mathrm{Ma}^{-1}\left(1 \mathrm{~mm} \mathrm{a}^{-1}\right)$ should, in principle, be detectable in quartz having $75-100 \mathrm{ppm} \mathrm{Al}$. Since erosion rates in much of the world are lower than $1 \mathrm{~km} \mathrm{Ma}^{-1}$, our hypothesis, if shown to be valid, could have wide application.

The reasoning we have presented suggests that our model is probably best applied to sediment collected from higher-order streams in areas unaffected by deep landsliding or glaciation. In addition, the validity of assuming that $\bar{C}_{\mathrm{SED}}^{J}=\bar{C}_{\mathrm{SOL}}^{J}$ remains untested. Studying cores or deposits may overcome problems associated with the assumption of isotopic steady-state and sediment mixing, and in favourable cases may indicate both the age of the core (Lal and Arnold, 1985) and the variability in erosion rate or sediment sources through time. However, for erosion rates calculated with our model to be of any value, landscapes and their geologic history will need to be considered carefully on a case by case basis.

\section{ACKNOWLEDGEMENTS}

This research was supported by grants NSF EAR-9004252 and NSF EAR-9396261 to P. R. Bierman and A. R. Gillespie, and by a DOE Global Change graduate fellowship to E. J. Steig. This manuscript and the ideas presented were improved by discussions with or reviews by W. Dietrich, D. Miller, T. Dunne, D. Montgomery, M. Pavich, A. Gillespie, C. Massey and an unnamed reviewer.

\section{REFERENCES}

Benda, L. E. and Dunne, T. 1987. Sediment Routing by Debris Flow, International Association of Hydrological Sciences, Publication $165,213-223$.

Bierman, P. R. 1994. 'Using in situ cosmogenic isotopes to estimate rates of landscape evolution: A review from the geomorphic perspective', Journal of Geophysical Research, 99, 13885-13896.

Bierman, P. R. and Gillespie, A. R. 1991. 'Range fires: A significant factor in exposure-age determination and geomorphic surface evolution', Geology, 19, 641-644.

Bierman, P. R. and Gillespie, A. R. 1992. 'Reply to comment on "Range fires: A significant factor in exposure-age determination and geomorphic surface evolution”, Geology, 20, 283-285.

Brown, E. T., Edmond, J. M., Raisbeck, G. M., Yiou, F., Kurz, M. D. and Brook, E. J. 1991a. 'Examination of surface exposure ages of Antarctic moraines using in situ produced ${ }^{10} \mathrm{Be}$ and ${ }^{26} \mathrm{Al}$ ', Geochimica et Cosmochimica Acta, 55, 2269-2283.

Brown, E. T., Raisbeck, G. M., Yiou, F., Kurz, M. and Brook, E. J. 1991b. 'Effective attenuation lengths of cosmic rays producing $\mathrm{Be}-10$ and 26-Al in quartz: implications for exposure dating', EOS, 72, 575.

Brown, L., Pavich, M., Hickman, R. E., Klein, J. and Middleton, R. 1988. 'Erosion of the eastern United States observed with ${ }^{10}$ Be', Earth Surface Processes and Landforms, 13, 441-457.

Cerling, T. E. 1990. 'Dating geomorphic surfaces using cosmogenic ${ }^{3} \mathrm{He}$ ', Quaternary Research, 33, $148-156$.

Cerling, T. E. 1991 . 'Dating catastrophic flood events using ${ }^{3} \mathrm{He}$ and ${ }^{21} \mathrm{Ne}$, Geological Society of America Abstracts with Programs, 23, A98.

Craig, H. and Poreda, R. J. 1986. 'Cosmogenic ${ }^{3}$ He in terrestrial rocks: The summit lavas of Maui', Proceedings of the National Academy of Science, 83, 1970-1974.

Dietrich, W. E. and Dunne, T. 1978. 'Sediment budget for a small catchment in mountainous terrain', Zeitschrift fur Geomorphologie, Supplement 29, $191-206$.

Dockhorn, B., Neumaier, S., Hartmann, F. J., Faestermann, H., Korschinek, G., Morinaga, H. and Nolte, E. 1991. 'Determination of erosion rates with cosmic ray produced ${ }^{36} \mathrm{Cl}$ ', Hadrons and Nuclei, 341, 117-119.

Donnelly, T. W. 1982. 'Worldwide continental denudation and climatic detcrioration during the late Tertiary: evidence from deep-sea sediments', Geology, 10, 451-454.

Elmore, D. and Phillips, F. 1987. 'Accelerator mass spectrometry for measurement of long-lived radioisotopes', Science, 236, 543-550. 
Gillespie, A. R. and Bierman, P. R. 1991. 'Theoretical precision estimates for exposure- age and erosion-rate data from analysis of cosmogenic isotopes', Geological Society of America Abstracts with Programs, 23, A409.

Jull, A. J., Wilson, A., Burr, G. S., Toolin, L. J. and Donahue, D. J. 1992. 'Measurements of cosmogenic ${ }^{14} \mathrm{C}$ produced by spallation in high-altitude rocks', Radiocarbon, 34, 737-744.

Klein, J., Giegengack, R., Middleton, R., Sharma, P., Underwood, J. R. and Weeks, R. A. 1986. 'Revealing histories of exposure using in situ produced ${ }^{26} \mathrm{Al}$ and ${ }^{10} \mathrm{Be}$ in Libyan desert glass', Radiocarbon, 28, 547-555.

Kohl, C. P. and Nishiizumi, K. 1992. 'Chemical isolation of quartz for measurement of in-situ-produced cosmogenic nuclides', Geochimica et Cosmochimica Acta, 56, 3583-3587.

Kurz, M. D. 1986. 'In situ production of terrestrial cosmogenic helium and some applications to geochronology', Geochimica et Cosmochimica Acta, 50, 2855-2862.

Kurz, M. D., Colodner, D., Trull, T. W., Moore, R. and O'Brien, K. 1990. 'Cosmic ray exposure dating with in situ produced cosmogenic ${ }^{3} \mathrm{He}$ : results from young Hawaiian lava flows', Earth and Planetary Science Letters, 97, 177-189.

Lal, D. 1988. 'In situ-produced cosmogenic isotopes in terrestrial rocks', Annual Reviews of Earth and Planetary Science, 16, 355-388.

Lal, D. 1991. 'Cosmic ray labeling of erosion surfaces: In situ production rates and erosion models', Earth and Planetary Science Letters, $104,424-439$.

Lal, D. and Arnold, J. R. 1985. 'Tracing quartz through the environment', Proceedings of the Indian Academy of Science (Earth and Planetary Science), 94, 1-5.

Lal, D., Nishizumi, K., Klein, J., Middleton, R. and Craig, H. 1987. 'Cosmogenic ${ }^{10} \mathrm{Be}$ in Zaire alluvial diamonds: implications for ${ }^{3} \mathrm{He}$ contents of diamonds', Nature, 328, 139-141.

Leavy, B. 1987. Surface-exposure dating of young volcanic rocks using the in situ buildup of cosmogenic isotopes, Ph.D. thesis, New Mexico Institute of Mining and Technology.

Marti, K. and Craig, H. 1987. 'Cosmic-ray-produced neon and helium in the summit lava of Maui', Nature, 325, 335-337.

Milliman, J. D. and Meade, R. H. 1983. 'Worldwide delivery of river sediment to the oceans', Journal of Geology, 91, 1-21.

Molnar, P. and England, P. 1990. 'Late Cenozoic uplift of mountain ranges and global climate change: chicken or egg?', Nature, 346, $29-34$.

Nishiizumi, K., Winterer, E. L., Kohl, C. P., Klein, J., Middleton, R., Lal, D. and Arnold, J. R. 1989. 'Cosmic ray production rates of ${ }^{10} \mathrm{Be}$ and ${ }^{26} \mathrm{Al}$ in quartz from glacially polished rocks', Journal of Geophysical Research, 94, 17907-17915.

Nishiizumi, K., Kohl, C. P., Arnold, J. R., Klein, J., Fink, D. and Middleton, R. 1991a. 'Cosmic ray produced ${ }^{10} \mathrm{Be}$ and ${ }^{26} \mathrm{Al}$ in Antarctic rocks: exposure and erosion history', Earth and Planetary Science Letters, 104, 440-454.

Nishiizumi, K., Kohl, C. P., Shoemaker, E. M., Arnold, J. R., Klein, J., Fink, D. and Middleton, R. 1991b. 'In situ ${ }^{10}$ Be- ${ }^{26}$ Al exposure ages at Meteor Crater, Arizona', Geochimica et Cosmochimica Acta, 55, 2699-2703.

Phillips, F. M., Zreda, M. G., Smith, S. S., Elmore, D., Kubik, P. W. and Sharma, P. 1990. 'Cosmogenic Chlorine-36 chronology for glacial deposits at Bloody Canyon, eastern Sierra Nevada', Science, 248, 1529-1532.

Phillips, F. M., Zreda, M. G., Smith, S. S., Elmore, D., Kubik, P. W., Dorn, R. I. and Roddy, D. J. 1991. 'Age and geomorphic history of Meteor Crater, Arizona from cosmogenic ${ }^{36} \mathrm{Cl}$ and ${ }^{14} \mathrm{C}$ in rock varnish', Geochimica et Cosmochimica Acta, 55, $2695-2698$.

Raymo, M. E. and Ruddiman, W. F. 1988. 'Influence of late Cenozoic mountain building on ocean geochemical cycles', Geology, 16, 649-653.

Reedy, R. C., Arnold, J. R. and Lal, D. 1983. 'Cosmic ray record in solar system matter', Science, 219, $127-135$.

Reneau, S. L. and Dietrich, W. E. 1991. 'Erosion rates in the southern Oregon Coast Range: evidence for an equilibrium between hillslope erosion and sediment yield', Earth Surface Processes and Landforms, 16, 307-322.

Reneau, S. L., Dietrich, W. E., Rubin, M., Donahue, D. J. and Jull, A. J. T. 1989. 'Analysis of hillslope erosion rates using dated colluvial deposits', Journal of Geology, 97, 45-63.

Saunders, I. and Young, A. 1983. 'Rates of surface processes on slopes, slope retreat, and denudation', Earth Surface Processes and Landforms, 8, 473-501.

Stuiver, M. and Quay, P. D. 1980. 'Changes in atmospheric carbon-14 attributed to a variable sun', Science, 207, 11-19.

Tric, E., Valet, J. P., Tucholka, P., Paterne, M., Labeyrie, L., Guichard, F., Tauxe, L. and Fontugne, M. 1992. 'Paleointensity of the geomagnetic field during the last 80,000 years', Journal of Geophysical Research, 97, 9337-9351.

Zreda, M. G., Phillips, F. M., Elmore, D., Kubik, P. W., Sharma, P. and Dorn, R. I. 1991. 'Cosmogenic chlorine-36 production rates in terrestrial rocks', Earth and Planetary Science Letters, 105, 94-109.

\section{NOTATION}

$$
\begin{aligned}
a_{i} & =\text { area of basin at subunit elevation } z\left(\mathrm{~cm}^{2}\right) \\
a_{\mathrm{T}} & =\text { total area of basin }\left(\mathrm{cm}^{2}\right) \\
C & =\text { isotope abundance }\left(\text { atoms } \mathrm{g}^{-1}\right) \\
C_{0} & =\text { isotope abundance at ground surface }\left(\mathrm{atoms}^{-1}\right) \\
C_{\text {init }} & =\text { isotope abundance at start of transport }\left(\mathrm{atoms}^{-1}\right) \\
C_{x} & =\text { isotope abundance at depth } x\left(\text { atoms } \mathrm{g}^{-1}\right) \\
\bar{C}_{\text {OUT }}^{J} & \left.=\text { average isotope concentration in mineral } J \text { leaving basin (atoms } \mathrm{g}^{-1}\right) \\
\bar{C}_{\text {SED }}^{J} & \left.=\text { average isotope concentration in mineral } J \text { in sediment leaving basin (atoms } \mathrm{g}^{-1}\right) \\
E, L, G & =\text { corrections for elevation, latitude and geometry } \\
f^{J} & =\text { fractional abundance of mineral phase in which isotope abundance is measured } \\
I_{\mathrm{D}} & \left.=\text { in situ produced decay isotope flux (atoms a }{ }^{-1}\right)
\end{aligned}
$$


$I_{\mathrm{IN}}=$ in situ produced incoming isotope flux (atoms $\mathrm{a}^{-1}$ )

$I_{\text {OUT }}=$ in situ produced outgoing isotope flux (atoms $\mathrm{a}^{-1}$ )

$I_{\mathrm{SED}}=$ in situ produced outgoing isotope flux in sediment (atoms $\mathrm{a}^{-1}$ )

$I_{\mathrm{SOL}}=$ in situ produced outgoing isotope flux in solution (atoms $\mathrm{a}^{-1}$ )

$I_{\text {TRAN }}=$ in situ produced isotope flux transported out of basin (atoms $\mathrm{a}^{-1}$ )

$J=$ specific mineral phase

$m=$ site specific rate of mass loss $\left(\mathrm{g} \mathrm{cm}^{-2} \mathrm{a}^{-1}\right)$

$\bar{m}=$ basin-wide average rate of mass loss $\left(\mathrm{g} \mathrm{cm}^{-2} \mathrm{a}^{-1}\right)$

$M_{\mathrm{IN}}=$ mass into reach of river or basin $\left(\mathrm{g} \mathrm{a}^{-1}\right)$

$M_{\text {OUT }}=$ mass out of reach of river or basin $\left(\mathrm{g} \mathrm{a}^{-1}\right)$

$N=$ isotope concentration (atoms $\mathrm{g}^{-1}$ )

$N_{\text {res (m) }}^{J}=$ mineral specific isotope inventory in basin of area $a_{\mathrm{T}}$ at mass loss rate $m$ (atoms)

$P_{0}=$ production rate at ground surface (atoms a $\mathrm{g}^{-1}$ )

$P_{0 \text { eff }}=$ effective basin-wide production rate at ground surface (atoms $\mathrm{a}^{-1} \mathrm{~g}^{-1}$ )

$P_{\mathrm{t} \text { eff }}=$ effective production rate during transport (atoms $\mathrm{a}^{-1} \mathrm{~g}^{-1}$ )

$P_{x}=$ production rate at depth $x$ (atoms a $\mathrm{a}^{-1} \mathrm{~g}^{-1}$ )

$P_{x \text { eff }}=$ effective basin-wide production rate at depth $x\left(\right.$ atoms $\mathrm{a}^{-1} \mathrm{~g}^{-1}$ )

$t=$ exposure age (a)

$t_{\mathrm{t}}=$ effective transport time or exposure duration (a)

$x=$ depth below ground surface $(\mathrm{cm})$

$x_{\mathrm{eff}}=$ effective depth for irradiation during transport $(\mathrm{cm})$

$z=$ elevation ( $\mathrm{m}$ above MSL)

$\varepsilon=$ lowering (erosion) rate $\left(\mathrm{cm} \mathrm{a}^{-1}\right)$

$\lambda=$ decay constant $\left(\mathrm{a}^{-1}\right)$

$\Lambda=$ attenuation factor $\left(\mathrm{g} \mathrm{cm}^{-2}\right)$

$\rho=$ density $\left(\mathrm{g} \mathrm{cm}^{-3}\right)$ 